\title{
LIMITES E PERSPECTIVAS DA TRANSIÇÃO AGROECOLÓGICA EM ASSENTAMENTOS RURAIS NO NORDESTE PARAENSE
}

\section{André Carlos de Oliveira Rochal Henderson Gonçalves Nobre ${ }^{2}$}

Resumo: A crise ambiental está ligada ao modo de produção capitalista. A Revolução Verde mudou o jeito de fazer agricultura no mundo, deixando de ser baseada no trabalho e nos recursos naturais, para ser baseada em capital. Os (as) camponeses (as) tem resistido a este modelo, realizando o que hoje se denomina de Agroecologia, que vem sendo defendida pelo Movimento dos Trabalhadores Rurais Sem Terra (MST). Objetivouse, investigar e discutir as limitações e perspectivas de processos de transição agroecológica dentro do contexto da reforma agrária. Para esta investigação foi utilizada a pesquisa qualitativa, através de pesquisa-ação, com abordagem materialista-histórica e dialética. Na coleta de dados foram utilizadas entrevistas semi-estruturadas, rodas de conversas, observação participante, pesquisa documental, bibliográfica e registros fotográficos. $\mathrm{O}$ método de análise dos dados foi a hermenêutica-dialética. Pode-se extrair seis limitações e seis perspectivas no processo de transição agroecológica, dentro do MST. Conclui-se que as ações do capitalismo no campo requerem que os movimentos de transformação saiam da lógica da resistência para a construção de uma ofensiva camponesa. Os limites apresentados só serão superados por uma práxis transformadora. Assim, a Agroecologia só se constrói com luta, relações sociais dialógicas, autonomia, organização e trabalho coletivo.

Palavras-chave: Agroecologia; Reforma Agrária; Campesinato; Amazônia.

${ }^{1}$ Eng $^{\circ}$. Agrônomo - Movimento dos Trabalhadores Rurais Sem Terra. E-mail: agro.andre@yahoo.com.br

${ }^{2}$ Docente na Universidade Federal Rural da Amazônia. E-mail: hendersonnobre@gmail.com 
Abstract: The environmental crisis is linked to the capitalist mode of production. The Green Revolution changed the way to do agriculture in the world, leaving to be based in the labor and natural resources, to be based on capital. The peasants have resisted to this model, carrying out what is now called Agroecology, what is defend by The Landless Rural Workers Movement (MST). It aims to investigate and discuss the limitations and perspectives of processes of agroecological transition within the context of agrarian reform. For this research was used qualitative research, through the action-research with a materialist-historical and dialectical approach. In the data collection, were used semi-structured interview, conversation circles, participant observation, documentary and bibliographical research and photographic records. The method of data analysis was hermeneuticdialectic. Six limitations can be drawn, as well as six perspectives in the process transition of agroecology. It is concluded that the actions of capitalism in the countryside require that the movements of transformation move from the logic of resistance to the construction of a peasant offensive. The limits presented will only be overcome by a transformative praxis. Thus, the Agroecology is only constructed with struggle, dialogical social relations, autonomy, organization and collective work.

Keywords: Agroecology; Agrarian Reform; Peasantry; Amazon

\section{Introdução}

A crise ambiental, tema mais que atual, está ligada diretamente às ações e atividades humanas de modo a reproduzirem sua existência, sendo nesta atualidade orientadas principalmente pelo modo de produção capitalista. Dentre estas atividades, influenciando fortemente, está a agricultura. Löwy (2014, p. 39-40) afirma ser "evidente que a corrida louca atrás do lucro, a lógica produtivista e mercantil da civilização capitalista/industrial nos leva a um desastre ecológico de proporções incalculáveis”.

Criar um mundo sustentável é fundamental para sobrevivermos a esta crise ambiental, colocando a relação entre as pessoas e o planeta no centro das prioridades. Contudo, afirma Empson (2014, p. 11, tradução nossa), que "isto exigirá uma ruptura radical com nossa sociedade existente".

O modo de produção capitalista, por conta de suas desigualdades gerou uma crise alimentar e que, segundo a Organização das Nações Unidas para Agricultura e Alimentação - FAO/ONU (2015), atualmente 793 milhões de pessoas não tem alimentos suficiente para manter sua saúde e suas atividades básicas. Uma estratégia surgida após a $2^{\text {a }}$ guerra mundial para resolver o problema da fome foi a chamada Revolução Verde. Esta mudou substancialmente o modo de fazer agricultura no mundo, passando de um saber fazer baseado no trabalho e nos recursos naturais, para um alicerce baseado em capital, a exemplo dos agrotóxicos e fertilizantes minerais solúveis, maquinários e progressivo controle das sementes e da biotecnologia.

Restou aos camponeses e camponesas a resistência ao modelo da Revolução Verde, pois ao longo da história da humanidade, sempre cumpriram o papel de produzir alimentos, manejando e conservando a agrobiodiversidade ao domesticarem e melhorarem sementes, plantas e animais. Como afirmam Sevilla Guzmán e Molina (2008, p. 11), esta estratégia constitui-se nas bases do que chamamos hoje de Agroecologia, configurando-se como uma importante alternativa para solucionar os problemas socioambientais, pois visibiliza as dimensões sociais e políticas na construção de uma agricultura sustentável. A Agroecologia é aqui considerada como alternativa para a agricultura familiar, pois ela busca ser altamente produtiva, sendo ambientalmente correta, socialmente justa e economicamente viável (ALTIERI, 2012; MACHADO; MACHADO FILHO, 2014; GLIESSMAN, 2005).

Desta forma, a passagem da agricultura hegemônica convencional para a Agroecologia é denominada, por muitos autores, de transição agroecológica (ALTIERI, 2012; GLIESSMAN, 2005). Contudo Machado e Machado Filho (2014) defendem que é necessária uma desconstrução, uma ruptura com a agricultura da Revolução Verde.

Outro ponto importante, mas que carece ser aprofundado em relação à Agroecologia, diz respeito à estrutura fundiária, que no Brasil permanece a mesma há 500 anos. Baseada no latifúndio, a estrutura agrária brasileira permanece intocável, sem a realização de uma profunda e verdadeira reforma agrária. Sem que os camponeses e camponesas tenham terra, não é possível desenvolverem sua agricultura; o agronegócio, porém, segue reproduzindo o modelo predatório de agricultura da Revolução Verde.

Neste cenário da atual estrutura agrária emerge o Movimento dos Trabalhadores Rurais Sem Terra (MST), que é referência de luta pela terra no Brasil, e tem defendido a Agroecologia em seu programa de Reforma Agrária Popular (MOVIMENTO, 2015). Deste modo, se faz importante trazer os camponeses e camponesas para o centro do debate acadêmico, pois estes foram ao longo dos anos marginalizados pela ciência. Como afirma Ploeg (2008, p. 243), a ciência tem duas faces que se relacionam com a área 
agrária; uma é a estabelecida, e está associada à padronização de regras e "contribui intensamente para a estruturação Imperial do mundo". A outra face, que tem "sempre uma relação ligeiramente desconfortável com sua parte estabelecida", valoriza as localidades, as experiências e as novidades (PLOEG, 2008, p. 243).

Assim, são fundamentais os trabalhos que discutem o campesinato e suas organizações, a exemplo do Movimento dos Trabalhadores Rurais Sem Terra (MST), e como estas vem construindo suas alternativas à agricultura capitalista e desenvolvendo a Agroecologia.

Feitas estas considerações iniciais, objetiva-se, com este trabalho, analisar e refletir nas limitações e perspectivas de processos de transição agroecológica dentro do contexto da reforma agrária, a partir de uma pesquisa-ação com famílias camponesas em assentamentos e acampamentos localizados no nordeste paraense e ligados ao Movimento dos Trabalhadores Rurais Sem Terra (MST).

\section{Referencial Teórico}

\section{Agroecologia}

Não existe um consenso na conceituação da Agroecologia, muito pelo fato de ser uma área de estudo nova e multidisciplinar, que emerge com o aporte de diversas outras áreas. Como ciência, Altieri (2012, p. 104) define "como a aplicação dos conceitos e princípios ecológicos para desenhar agroecossistemas sustentáveis" e que "sejam culturalmente adaptados e social e economicamente viáveis".

Para Gliessman (2005), a Agroecologia é uma nova abordagem da agricultura e do desenvolvimento sustentável, fundamentada na conservação dos recursos da agricultura tradicional local, associado ao conhecimento da ecologia moderna. Mais diretamente, "é definida como a aplicação de conceitos e princípios ecológicos no desenho e manejo de agroecossistemas sustentáveis".

A Agroecologia é entendida por Machado e Machado Filho (2014, p. 36 , grifo do autor)

como um método, um processo de produção agrícola - animal e vegetal - que resgata os saberes que a 'revolução verde' destruiu ou escondeu, incorporando-lhes os extraordinários progressos científicos e tecnológicos dos últimos 50 anos, configurando um corpo de doutrina que viabiliza a produção de alimentos e produtos limpos, sem venenos, tanto de origem vegetal como animal, e, o que é fundamental, básico, indispensável, em qualquer escala. É, pois, uma tecnologia capaz de confrontar o agronegócio, em qualquer escala.

Atualmente, no Brasil, a Agroecologia é utilizada, em várias frentes, desde a construção de práticas educativas, conjunto de técnicas, crítica ecológica, até a crítica ao agronegócio (NUNES, 2014). Porém Padula et al. (2013, p. 69), sintetiza que "o Brasil vem se destacando na construção do campo agroecológico na perspectiva dos três significados possíveis da Agroecologia: movimento social, prática e ciência".

A Agroecologia carrega uma perspectiva altamente transformadora, ela "fornece as bases científicas, metodológicas e técnicas para uma nova revolução agrária não só no Brasil, mas no mundo inteiro" (ALTIERI, 2012, p. 15, grifo do autor). Iniciativas nas perspectivas agroecológicas são fundamentais para os camponeses e camponesas, pois representam

a possibilidade de acesso a terras, sementes, água, crédito e mercados locais, por meio da criação de políticas de apoio econômico, do fornecimento de incentivos financeiros, da abertura de oportunidades de mercado e da disponibilidade de tecnologias agroecológicas (ALTIERI, 2012, p. 15).

Altieri (2012, p. 17) avalia que "apesar dos avanços obtidos por movimentos agroecológicos, ainda existem muitos fatores que têm limitado ou restringido sua plena disseminação e implementação". Os entraves para o avanço da Agroecologia estão no campo das políticas públicas, das instituições e dos programas de pesquisa e desenvolvimento, além de conflitar com poderosos interesses econômicos e institucionais (ALTIERI, 2012; MACHADO; MACHADO FILHO, 2014).

Esses interesses são, na verdade, um sistema agroalimentar industrial, um modelo no qual a agricultura do tipo capitalista está inserida e que Ploeg (2008) denomina de "Império Alimentar", que constitui um regime, um modus operandis que tende a tornar-se dominante. Como o autor afirma, "ao mesmo tempo, o Império é personificado por uma variedade de expressões específicas: grupos do agronegócio, grandes varejistas, mecanismos estatais, mas também leis, modelos científicos, tecnologias, etc". Como alternativa a esse sistema e solução para a agricultura camponesa, Altieri (2012, p. 
19) defende a construção de alternativas agroecológicas que se adaptem às necessidades da agricultura familiar e das populações de baixa renda.

Os movimentos sociais, principalmente ligados ao campo, têm, há alguns anos, assumido a Agroecologia como bandeira de luta (ALTIERI, 2012). Para Rosset e Martínez Torres (2016), os movimentos sociais, se utilizam da Agroecologia, para disputar o território, o que é bem marcante na Via Campesina. No entendimento dos autores, os movimentos sociais fazem o contraponto da "agricultura agroecológica realizada por camponeses, povos indígenas e agricultores familiares com as práticas destrutivas e alimentos pouco saudáveis produzidos pela agricultura industrial e o agronegócio".

O início do debate agroecológico nos movimentos sociais no Brasil, vale a ressalva, começou a tomar força tardiamente, como exemplo, no MST e na Via Campesina, isso se deu apenas na década de 1990 (PADULA et al, 2013). Porém, nos dias atuais o Movimento dos Trabalhadores Rurais Sem Terra (MST) tem a Agroecologia como principal ferramenta para "mudar o modelo tecnológico e produtivo dos assentamentos em particular e da agricultura brasileira em geral" (COORDENAÇÃO, 2010, p. 14).

Considerando o contexto amazônico, existe uma dificuldade de se entender a Agroecologia nessa região, que além da agricultura familiar camponesa, inclui outras categorias diferenciadas do restante do país, como por exemplo, ribeirinhos, indígenas, extrativistas e pescadores (PADULA et al., 2013). Os sistemas de produção das populações tradicionais da Amazônia vão além da dimensão ecológica da Agroecologia, o que implica na necessidade de uma abordagem transdisciplinar, a fim de se trilhar os caminhos da transição agroecológica e contribuir para o desenvolvimento endógeno da região (SÁ; SILVA, 2014).

\section{Extensão Rural}

A Assistência Técnica e Extensão Rural - ATER cumpre um papel estratégico na agricultura, seja para reprodução e manutenção do status $q u o$, dos paradigmas, do modelo, ou para a transformação e superação do mesmo. Segundo Nunes et al. (2013, p. 41), a ATER é estratégica para o agronegócio, pois auxiliam na manutenção e ampliação do mercado, contribuem para avançar em novas frentes, e beneficiar-se de subsídios oferecidos pelo governo.

Freire (2011) questiona o termo "Extensão" que, como um método de levar o conhecimento aos camponeses e camponesas desconsiderando suas histórias, realidades, culturas e saberes, serve somente para manter a situação de opressão, por mais bem intencionado que o profissional possa estar. O autor (Ibid.) propõe o termo "Comunicação" que, considerando os saberes e conhecimentos dos atores sociais, bem como sua realidade histórica, remete a necessidade de diálogo, de uma relação de mão dupla, entre o extensionista e o (a) camponês (a), sendo capaz de contribuir com a transformação social.

A ATER atual, dentro do modelo capitalista de agricultura favorecido pela concentração do capital agroindustrial, orienta-se pela estreita relação com a indústria de insumos, interferindo assim, na política de ATER pautada pelos princípios agroecológicos (NUNES et al., 2013).

Para Caporal (2007a, p. 62), a Extensão Rural, que se adequada aos pressupostos teóricos do desenvolvimento sustentável, pode ser

uma proposta de ação compatível com as demandas e com a realidade do nosso tempo, mostrando que continua sendo uma atividade capaz de adequar-se às condições históricas, de modo a dar as respostas que são exigidas pela sociedade a quem serve, contribuindo para a construção do desenvolvimento econômico e social.

Caporal (2007b, p. 100) defende que existe um processo de mudança em curso no sentido de um novo paradígma de Extensão Rural, materializado na atual política de ATER, a Política Nacional de Assistência Técnica e Extensão Rural - PNATER(BRASIL, 2007), que incorpora parte dos princípios agroecológicos. Esta, mesmo com a dificuldade de por em prática uma ATER baseada na Agroecologia, se mostra bem diferente da convencional (CAPORAL, 2007c).

A pesar da nova Lei de ATER definir como meta o acesso universal à ATER pública, os agricultores e agricultoras familiares atendidos pela Empresa de Assistência Técnica e Extensão Rural do Estado do Pará (EMATER-PA) giram em torno de $50 \%$ do público total atendido com ATER, isso considerando o estado do Pará como um todo (SILVA et al., 2006). Considerando as ações de ATER nos assentamentos, os autores afirmam que a quantidade de técnicos é insuficiente para o Território do Nordeste Paraense.

Ademais de não chegar à ampla maioria dos agricultores beneficiários, a Assistência Técnica e Extensão Rural na Amazônia tem como principais problemas, de modo geral, a má qualidade nos serviços; o não respeito 
do calendário agrícola quanto à liberação de crédito; técnicos não identificados com a agricultura familiar; equipes limitadas quanto a inter e multidisciplinaridade; falta de infraestrutura; além da necessidade de considerar, de forma participativa, os diversos segmentos: camponeses(as) de fronteira, indígenas, quilombolas, ribeirinhos(as) e extrativistas (SILVA et al., 2006).

Desta forma, se faz necessário, no estado do Pará o aprimoramento e regionalização dos projetos de apoio à agricultura familiar, sendo que, no caso específico do Nordeste Paraense, a recuperação dos solos e a recomposição florestal com sistemas agroflorestais, orientados por uma ATER baseada em uma matriz agroecológica (GUEDES; FERREIRA, 2006).

\section{Reforma Agrária e a organização do Movimento dos Trabalhadores Rurais Sem Terra - MST}

A estrutura agrária brasileira é hegemonizada pelo latifúndio. Fruto das políticas implantadas pela Coroa portuguesa, e perpetuada nas políticas imperiais e republicanas, o latifúndio tem impactos negativos no desenvolvimento do Brasil. Stedile (2003) chega a denominá-lo de "o pecado agrário brasileiro" e cita, como exemplo dos impactos, o aumento do desemprego no campo, o aumento da violência no campo, o êxodo rural e consequente inchaço das cidades, levando igualmente ao aumento da violência.

A estrutura agrária do país permanece imutável e produzindo desigualdades. Como afirmam Rocha e Zuliani (2007, p. 86), "a realidade fundiária no Brasil contribui para a situação da miséria, fome e opressão do povo brasileiro".

Em trabalho contemporâneo à publicação do Estatuto da Terra de 1964, $1^{a}$ lei de Reforma Agrária do país, Moura $(1968$, p. 107) afirma, no que se refere à reforma agrária, "que ela se processaria nas áreas de emergência em que mais se acentuassem as tensões sociais". O autor (Ibid.) cita, ainda, trecho de discurso do então General Castelo Branco, rechaçando qualquer proximidade de perspectiva de uma reforma agrária pelo viés socialista. Ou seja, o objetivo meramente de reduzir as tensões sociais presentes no campo brasileiro, principalmente pela ação das Ligas Camponesas, do Movimento dos Agricultores Sem Terra (MASTER) e da União dos Lavradores e Trabalhadores Agrícolas do Brasil (ULTAB), sem no fundo buscar desenvolvimento econômico ou justiça social.

É importante ressaltar que a Reforma Agrária, no Estatuto da Terra, é entendida sob uma abordagem clássica, de apenas distribuição de terras, sem considerar outras políticas sociais como saúde, educação, infraestrutura etc. Para Prado Jr. (1979, p. 80), uma proposta de reforma agrária com perspectiva de resolver as questões agrárias brasileiras, deve "aceitar a alegação de que a divisão da terra e o amparo ao pequeno proprietário e produtor se acham conjugados".

Segundo Marques et al. (2012), baseado em dados do Censo 2006, existem 7.396 assentamentos no Brasil, 716.894 famílias assentadas, sendo que o Pará é o estado com maior número, 878 assentamentos $(11,87 \%$ do total), com 175.763 famílias (24,52\% do total).

Considerando a utilização das terras de reforma agrária, em relação a área aproveitável, no Brasil a área destinada à lavoura é de 18\%, pastagem $59 \%$ e agrofloresta 4\%; já na região norte essa relação é de $8 \%$ para lavoura, 65\% para pastagem e 3\% para agrofloresta; e no Pará, 6\% para lavoura, 67\% para pastagem e 4\% para agrofloresta (MARQUES et al., 2012).

Nos dados sobre ocupação, os assentamentos no Brasil são responsáveis por absorver 1.881.739 pessoas; na região norte esse número é de 520.021; e no Pará é de 199.872 pessoas ocupadas (MARQUES et al., 2012).

No atual programa agrário do MST, o Movimento defende uma Reforma Agrária Popular, que "tem como base a democratização da terra, mas busca produzir alimentos saudáveis para toda população; objetivo que o modelo do capital não consegue alcançar” (MOVIMENTO, 2015, p. 34).

O programa de Reforma Agrária Popular do MST, que objetiva mudanças estruturais na forma de uso dos bens da natureza, na organização da produção e nas relações sociais do campo, tem como fundamento oito pontos, sendo eles a terra, os bens da natureza, as sementes, a produção, a energia, a educação e cultura, os direitos sociais e as condições de vida para todos e todas (MOVIMENTO, 2015).

O Movimento dos Trabalhadores Rurais Sem Terra (MST) é fruto da história da luta pela terra, da luta de todos os povos expropriados ou ameaçados de serem expropriados da terra e que, assim, lutaram para defendê-la (ROCHA, 2015).

O surgimento do MST se deu, de certo modo, por consequências do modelo imposto da Revolução Verde, como os processos de mecanização e quimificação da agricultura, que resultou no empobrecimento e expulsão 
das pessoas do campo (muita terra com monocultura, pouca gente e pouco trabalho), criando as condições objetivas para a construção desse movimento de massas de luta pela terra e por Reforma Agrária (COORDENAÇÃO, 2010).

Fundado em 1984, o MST é um movimento social, organizado por uma parcela do campesinato e que luta por reforma agrária. Martins (2010) afirma que em um primeiro momento o MST reproduziu o modelo do capital para a agricultura, baseado em insumos sintéticos e mecanização pesada. Porém, passou a perceber e desenvolver uma crítica às implicações desse modelo, posição está assumida em seu IV congresso nacional, no ano 2.000. Sendo este o resultado de uma transição de um discurso com forte viés produtivista para outro mais condizente com os princípios agroecológicos, incorporando no centro de suas reivindicações o resgate da agricultura camponesa (BORSATTO; CARMO, 2013).

No sentido de entender melhor o MST, é importante conhecer seus objetivos e sua organicidade, com especial atenção para as particularidades no estado do Pará. Os principais objetivos do Movimento configuram-se na luta pela terra, a reforma agrária e o socialismo (MOVIMENTO, 2016).

As instâncias organizativas do MST, que são os espaços de tomada de decisão política, vão desde o núcleo de famílias nos acampamentos e assentamentos, até o congresso nacional da Organização. Para melhor execução das tarefas, o Movimento se organiza em setores e coletivos, dentre os quais o Setor de Produção, Cooperação e Meio Ambiente - SPCMA. (MOVIMENTO, 2016). A formação política sempre foi uma preocupação do MST, que organiza cursos formais e não-formais para seus militantes. Como afirma Pizetta (2007, p. 92), tudo é parte de um processo coletivo em construção e "que o trabalho de formação política é estratégico".

O MST no Pará está divido em quatro regionais, a Carajás, a Eldorado, a Araguaia e a Cabana, sendo que as três primeiras ficam na região Sul e Sudeste do estado e a Regional Cabana, corresponde aos assentamentos e acampamentos localizados no Nordeste Paraense. O processo de formação do MST-PA pode ser dividido em fases, que vão desde a luta posseira até uma articulação com outras categorias do campesinato amazônico, organizados na Via Campesina. E "atualmente o Movimento vem discutindo, fortemente, o papel dos assentamentos na luta social, passando a refletir sobre os assentamentos como centro das ações do MST". (ROCHA, 2009).

\section{Percurso Metodológico}

Para esta investigação foi utilizada a pesquisa-ação qualitativa com enfoque histórico-estrutural, que Triviños (1987) considera válido para nossa realidade social que, com auxílio do método dialético, é capaz de assinalar causas e conseqüências dos problemas, suas contradições e relações, qualidades e dimensões quantitativas, se existirem, visando um processo de transformação da realidade que interessa. Para Tse-Tung (2004) a teoria materialista-dialética do processo de desenvolvimento do conhecimento vai do superficial ao profundo e está fundamentada na prática.

Para Thiollent (2011, p. 20), “a pesquisa-ação é um tipo de pesquisa social com base empírica que é concebida e realizada em estreita associação com uma ação ou com a resolução de um problema coletivo", sendo que os (as) pesquisadores (as) e os (as) participantes interagem de modo cooperativo ou participativo.

O percurso metodológico da pesquisa-ação se deu por uma demanda da coordenação regional do MST, que propôs à reorganizar o setor de Produção, Cooperação e Meio Ambiente (SPCMA) em setembro de 2015, centrado em uma lógica de desenvolvimento e fortalecimento das experiências agroecológicas nas áreas de reforma agrária ligadas ao Movimento, no Nordeste Paraense.

É possível dividir a ação em quatro fases, nas quais se encontram as "técnicas utilizadas em pesquisa participante e pesquisa-ação (THIOLLENT, 2011, p. 99):

a) Encontro Regional do Setor de Produção, Cooperação e Meio Ambiente: realizado em novembro de 2015, com os camponeses e camponesas dos assentamentos e acampamentos da região, no qual se discutiu a importância da Agroecologia para o desenvolvimento da agricultura camponesa e definiu um coletivo responsável para assumir o processo nas áreas (um agricultor por assentamento ou acampamento). Também ocorreu um planejamento participativo do Setor de Produção, Cooperação e Meio Ambiente, realizado no assentamento João Batista, em Castanhal-PA, que contou com a presença de 70 pessoas de 11 comunidades.

b) Oficina Regional de Capacitação Técnica em Agroecologia: realização de duas oficinas sobre tecnologias agroecológicas (janeiro e junho de 2016), de cinco dias cada uma. Vale ressaltar que essa capacitação foi demandada pelos próprios camponeses e camponesas, fruto do planejamento. A primeira foi realizada no assentamento Mártires de Abril, em Mosqueiro-Belém-PA, e contou com 17 pessoas. A segunda foi realizada no assentamento João 
Batista e contou com a presença de 11 pessoas.

c) Formação Política e Planejamento Local: no intervalo das oficinas, durante todo o primeiro semestre de 2016, foi feita uma formação de dois dias, em cada assentamento ou acampamento, com enfoque na Agroecologia, baseado no dialogo entre conhecimento formal e não-formal. Foi encaminhado nestes espaços a construção de uma experiência coletiva de produção agroecológica, por assentamento ou acampamento, e foi realizado um diagnóstico da produção, feito pelos próprios camponeses e camponesas, em oito áreas, sendo quatro assentamentos e seis acampamentos (QUADRO 1).

Quadro 1 - Acampamentos e assentamentos participantes da pesquisa-ação.

\begin{tabular}{|l|c|c|c|}
\hline $\begin{array}{l}\text { NOME DA COMUNI- } \\
\text { DADE }\end{array}$ & MUNICÍPIO & $\begin{array}{c}\text { SITUAÇÃO DA } \\
\text { TERRA }\end{array}$ & $\begin{array}{c}\text { N}^{0} \text { de FA- } \\
\text { MÍLIAS }\end{array}$ \\
\hline Chico Mendes & Benevides & Acampamento & 70 \\
\hline Olga Benário & Acará & Acampamento & 20 \\
\hline Terra Cabana & Benevides & Acampamento & 100 \\
\hline Quintino Lira & Santa Luzia do Pará & Acampamento & 74 \\
\hline Carlos Marighela & Irituia & Acampamento & 54 \\
\hline Jesus de Nazaré & Santa Izabel do Pará & Acampamento & 70 \\
\hline Carlos Lamarca & Capitão Poço & Assentamento & 26 \\
\hline Luiz Carlos Prestes & Irituia & Assentamento & 48 \\
\hline João Batista & Castanhal & Assentamento & 154 \\
\hline Mártires de Abril & Belém & Assentamento & 92 \\
\hline
\end{tabular}

d) Avaliação Local: caracterizada pelo retorno, durante o segundo semestre de 2016, nos assentamentos e acampamentos avaliando coletivamente o processo, tendo como foco o que foi realizado; o que não teve êxito e o porquê; quais foram as dificuldades e as possíveis soluções para os problemas que apareceram.

A coleta de dados foi feita através de instrumentos participativos, como as rodas de conversas e observação participante realizada entre novembro de 2105 e novembro de 2016 em reuniões da Direção Estadual, da Direção
Regional do MST-PA, bem como dos espaços de reunião do Setor de Produção Cooperação e Meio Ambiente, seja a nível regional, estadual ou nacional, além de outros espaços pertinentes organizados pelo MST. Para tal, utilizou-se caderno de campo, onde foram registrados fatos, falas e reflexões. Adicionalmente, foi realizada pesquisa documental e bibliográfica, além de tomada de registros fotográficos.

Outro mecanismo de coleta de informações foram as entrevistas semiestruturadas com agricultores que participam do MST-PA, em instâncias de direção e/ou em assentamentos e acampamentos, realizadas em setembro de 2016, onde os eixos do roteiro versavam sobre o entendimento da Agroecologia, a importância do tema para o MST, as dificuldades de avançar na transição agroecológica e as perspectiva para o MST. Participaram seis agricultores/ militantes do Setor de Produção, Cooperação e Meio Ambiente - SPCMA, de âmbito regional, estadual e nacional do MST. Especificando as entrevistas: um dirigente nacional do SPCMA, uma dirigente estadual do SPCMA, dois coordenadores regionais do SPCMA e responsáveis por experiências agroecológicas familiares, uma responsável por experiência agroecológica familiar e uma militante responsável por um centro de formação política.

O método utilizado para a análise dos dados foi a hermenêutica-dialética, pois esta conduz o intérprete a buscar "entender o texto, a fala e o depoimento como resultado de um processo social (trabalho e dominação) e processo de conhecimento (expresso em linguagem) ambos frutos de múltiplas determinações, mas com significado específico" (MINAYO, 2000, p. 227), com foco nas categorias definidas no processo de pesquisa-ação, sendo elas: latifúndio, políticas públicas, trabalho e agronegócio.

\section{Resultados e Discussões}

A partir do processo de pesquisa-ação, pode-se extrair seis limitações ao desenvolvimento de processos que visam uma transição do modelo de agricultura convencional para outro modelo baseado em princípios da Agroecologia. A partir de uma leitura materialista-histórica e dialética da realidade, as limitações encontram suas antíteses nas perspectivas da Agroecologia, ou seja, os camponeses e camponesas do MST vêm respondendo, de alguma maneira aos desafios encontrados.

A primeira limitação encontrada é o latifúndio e a forma como os (as) camponeses (as) vem o enfrentando se dá através da organização e luta pela 
terra. Esse limite ao desenvolvimento de uma agricultura ecológica se dá por dois motivos principais. Primeiro que a terra é o fator de produção primário para o desenvolvimento da agricultura e, em segundo lugar, a violência oriunda dos latifundiários gera insegurança para o avanço da produção. $\mathrm{O}$ relato do acampado "A" retrata essa situação:

"se fizer, os caras vêm e destroem (...). O fazendeiro destruiu tudo, desde o início. Isso desanima, mas a gente continua na luta".

Esses conflitos se dão principalmente nas fases de acampamento. Como exemplo, durante o primeiro semestre de 2016, o acampamento Quintino Lira sofreu diversos ataques por parte do latifundiário, como agressões físicas e psicológicas, destruição de estruturas (casa de farinha) e plantações (Figura 1). Vale ressaltar que, em 2008, houve caso de assassinato e agressões físicas de acampados, sendo que atualmente o processo segue na justiça. Igualmente no primeiro semestre de 2016, outro acampamento, o Jesus de Nazaré, sofreu ataques por parte da pretensa dona da fazenda.

Frente a isso, esses camponeses e camponesas se organizam coletivamente, dentro da estrutura e estratégia do MST, para fazer conquistar a terra e reproduzirem sua existência. Afirma, o dirigente nacional do SPCMA "B", que:

"a Agroecologia é hoje para o MST um dos alicerces da Reforma Agrária Popular. Projeto político em que a Reforma Agrária se apresenta como demanda dos trabalhadores do campo e da cidade, não mais da burguesia".

Para que esse projeto se concretize Rocha (2009) afirma que o MST utiliza como forma de luta para pressionar o Estado por Reforma Agrária, a ocupação de terras, a formação de acampamentos e organização das famílias. Destarte que, ao transformar a terra em fator de produção e subsistência através do trabalho, força o Estado a fazer ações no sentido do desenvolvimento, créditos e Educação, de modo geral, para além do MST (ROSA, 2015).

Uma segunda limitação remete à expropriação do conhecimento, um dos prejuízos trazidos pela Revolução Verde e levado em prática pela Extensão Rural e instituições de pesquisa. Os camponeses e camponesas têm respondido a esse limite construindo processos dialógicos entre o saber popular e conhecimento científico. Esse limite pode ser observado nas falas do acampado "A", elucidando essa questão, quando diz que: "tenho pouca escolaridade, quem sou eu para passar esse conhecimento. Tem que vir professores formados".

Figura 1 - Plantação de pimenteira-do-reino e de bananeiras no acampamento Quintino Lira destruídas por jagunços dos fazendeiros.

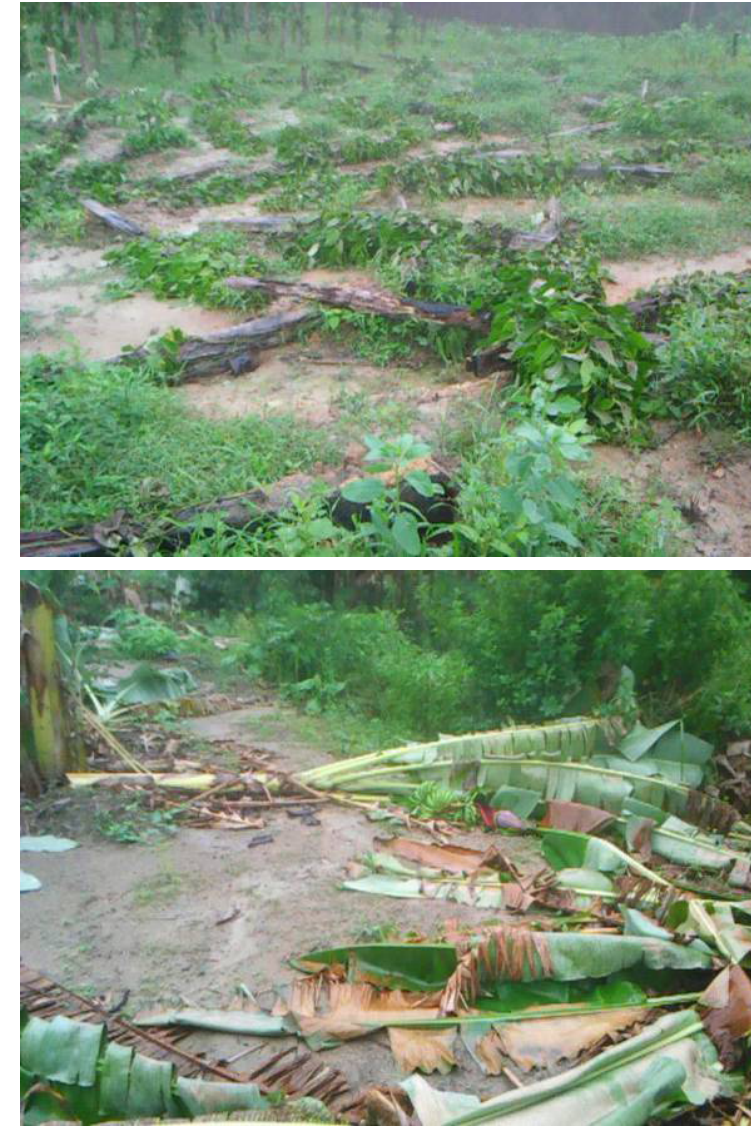

Fonte: Secretaria regional MST, 2016

Outro exemplo foi a grande demanda exposta no Encontro Regional do SPCMA por capacitação técnica sobre como fazer as práticas agroecológicas. Indo desde práticas mais simples como a da compostagem, passando por combate a pragas e doenças, até a preparação de roçados sem o uso do fogo. Essa necessidade gerou dois cursos de capacitação, organizados no processo da pesquisa-ação (Figura 2).

Os cursos foram baseados nos princípios de uma pedagogia libertadora (FREIRE, 2003), contando com a participação e contribuição da Empresa Brasileira de Pesquisa Agropecuária (EMBRAPA) e do Núcleo de 
Estudos, Pesquisas e Extensão em Agricultura Familiar e Agroecologia da Universidade Federal Rural da Amazônia/Campus Capitão Poço (NEAUFRA-CCP). Sempre esteve presente a preocupação de não ser uma prática domesticadora e de que

o trabalho do agrônomo não pode ser o de adestramento nem sequer o de adestramento dos camponeses nas técnicas de arar, de semear, de colher, de reflorestar etc. Se se satisfizer como um mero adestrar, pode, inclusive, em certas circunstâncias, conseguir uma maior rentabilidade do trabalho. Entretanto, não terá contribuído em nada para a afirmação deles como homens mesmos (FREIRE, 2011, p. 43).

Figura 2 - Construção de sistema permacultural de tratamento e utilização de águas cinzas.

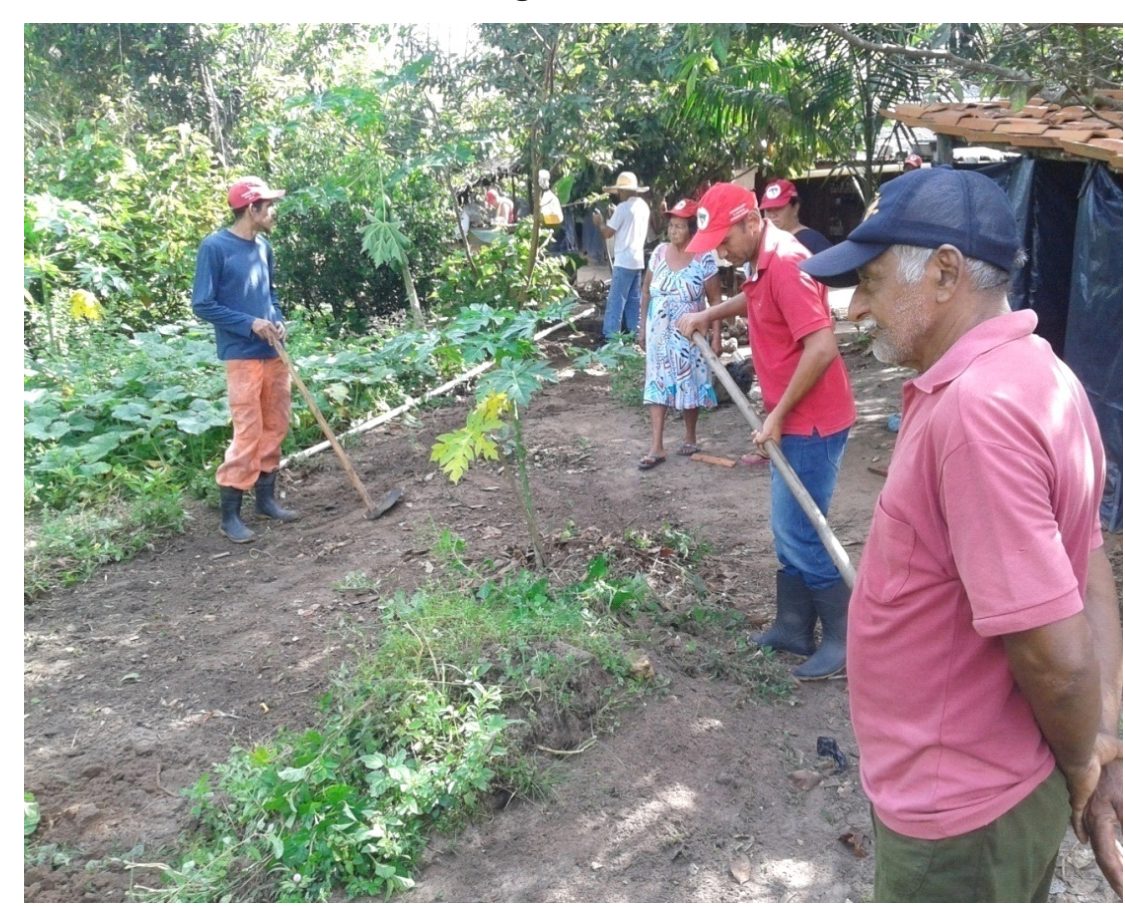

Fonte: Trabalho de campo (2016).

Portanto, os cursos foram baseados em um princípio da Agroecologia defendido por Faria (2014, p. 108), que afirma que "além dos conhecimentos e saberes populares, são fundamentais os conhecimentos científicos, os quais determinam com mais perfeição seus princípios e filosofias". Esta premissa também ficou expressa no depoimento do dirigente "B", quando afirma que: "a Agroecologia articula os conhecimentos científico e saberes tradicionais".

Quanto à importância do diálogo de saberes na construção da Agroecologia, o assentado " $\mathrm{C}$ " tem o entendimento de que

“o empirismo, ele deve estar sendo acompanhado pela questão técnico-científica e pra que a gente melhore, dentro de um conjunto de ideias, essa formação e essa organização da agricultura".

Junto com a expropriação de saberes promovida por instituições de pesquisa e pela ATER, o acesso à ATER também se configura em um limite, pois além de não existir uma política de assistência técnica para acampamentos, os assentamentos que fizeram parte do universo desta pesquisa não estão sendo assistidos por ela. Isso se deu pelo fato da empresa, que havia ganho a licitação para prestação do serviço, ter falido. $O$ assentado "C" fala que a assistência técnica, quando existe, é uma das dificuldades de se avançar na Agroecologia; na percepção dele

“essa assistência técnica, essas que são provindas das ATER's, ela se diferencia um pouco do nosso modelo de Agroecologia, incentivando mais essa questão tradicional de produzir e do manejo com a terra".

Continuando, para o dirigente "B" (grifo nosso),

“é necessário o controle sobre a ATES, uma vez que ONG's ou empresas que não tenham vínculo com a organização, pouco contribuíram além de uma mera substituição de insumos".

Coadunando assim com o estudo de caso feito por Nascimento et al. (2014), que igualmente mostrou ser necessário "uma intervenção participativa, com produtores e técnicos, na busca de estratégias de sustentabilidade".

Experiências de ATES e assessoria técnica própria do MST, vem ocorrendo no Nordeste paraense, muitas vezes de forma voluntariada, porém muito ligadas aos lotes familiares em transição agroecológica. Tem acontecido de forma isolada e esporádica, por estudantes e recém-formados de cursos técnicos e superior de instituições como Universidade Federal Rural da Amazônia (UFRA) e do Instituto Federal de Educação, Ciência e 
Tecnologia do Pará (IFPA).

As políticas públicas configuram-se também como um limite, visto que, ainda como fruto da Revolução Verde, as políticas para a agricultura camponesa e agricultura familiar (de crédito, assistência técnica, infraestrutura, incentivos etc.) são marginalizadas, dando-se preferência para ao Agronegócio. Isso pode ser visto, por exemplo, no montante de recursos destinado ao Plano Agrícola Pecuário (2017/2018), com R\$200,5 bilhões para a agricultura empresarial (MAPA,2017); e ao Plano Safra (2017/2018), com R \$30,0 bilhões para a agricultura familiar (SEAD, 2017).

Desta forma, todas as agricultoras e agricultores entrevistados na pesquisa relataram a ausência de políticas públicas, muito embora estas existam e não estejam acessíveis, fato este devido muitas vezes à burocracia institucional. Este limite que também esteve muito presente nas falas dos camponeses e camponesas nas atividades desenvolvidas, fica visível na fala da assentada "D":

“a gente vê que não tem política pública, não adianta dizer que tem, voltada para a produção camponesa (...). Nós temos um grande desafio que é esse, um grande entrave, porque o governo nosso, no Brasil, não tem política voltada pra essa agricultura familiar camponesa, ele só se preocupa mais com o agronegócio".

Adicionalmente, a conjuntura política atual do país preocupa os movimentos sociais, pois com a extinção do Ministério do Desenvolvimento Agrário (MDA) que tratava das questões referentes à agricultura familiar e à reforma agrária, paira incertezas quanto aos rumos das políticas voltados para o campesinato. A assentada "E" fala a esse respeito, pois se as dificuldades referentes às políticas públicas já eram grandes,

"hoje está cada vez mais acirrada com o golpe que a gente sofreu bem recentemente com o governo que ta aí, que não é legítimo, que a gente não legitima".

A Política Nacional de Agroecologia e Produção Orgânica (PNAPO) é um exemplo de construção relativamente positiva com o Governo Dilma (PADULA et al., 2013), que hoje está, se não ameaçada, no campo da incerteza devido a extinção do MDA.

Quanto ao INCRA, outro órgão público responsável pelas políticas de reforma agrária, Penna e Rosa $(2015$, p. 82$)$ lembram que "tanto para servidores, quanto para movimentos e beneficiários, o INCRA ainda se encontra longe de cumprir suas expectativas", porém a política de reforma agrária é uma malha com múltiplas determinações que não é estruturada somente em Brasília, na sede nacional do órgão. O que mostra que a queixa de ausência de política pública está na verdade no acesso dificultado pela burocracia estatal. Desta forma, é necessária, portanto, afirma o dirigente "B":

“a implantação de uma assistência técnica popular e agroecológica, a destinação de fomentos para a transição agroecológica, a simplificação da certificação e o apoio a processos de agroindustrialização".

Na ausência, de políticas públicas por parte do Estado e materializada pela inacessibilidade, os camponeses e camponesas do MST vêm construindo, como alternativa, experiências autônomas, com solidariedade de classe ou, como no caso do Assentamento Carlos Lamarca, com parceria institucional (QUADRO 2). No trabalho de Azevedo et al. (2013, p. 2278) sobre perspectivas agroecológicas no desenvolvimento rural de uma comunidade, observou-se que os agricultores e agricultoras "concentram esforços na dimensão comunitária e na realidade sociocultural que proporciona uma práxis intelectual e política da identidade local e de sua rede de relações sociais". Como expressa a assentada "E", o MST vem se desafiando a construir

"permanentemente experiências, experimentações do próprio campesinato, que vem aí se forjando dentro da Agroecologia, no sentido de criar uma forma, ecos".

Esta construção também é representada na fala do assentado " $\mathrm{C}$ ":

"a Agroecologia vem acontecendo pelo esforço espontâneo da sociedade, da conscientização".

As principais experiências observadas na pesquisa-ação são: Lote Agroecológico de Produção Orgânica (LAPO), o Lote Agroecológico Ernesto e Taiguara (LAET), o Sistema Agroecológico de Produção Orgânica (SAPO) e as experiências coletivas do assentamento Carlos Lamarca, este último em parceria com a Universidade Federal Rural da Amazônia (UFRA), campus Capitão Poço, mais especificamente o Núcleo de Estudos, Pesquisas e Extensão em Agricultura Familiar e Agroecologia (NEA-UFRA-CCP). 
Quadro 2 - Experiências agroecológicas do MST no nordeste paraense

\begin{tabular}{|l|l|l|l|}
\hline \multicolumn{1}{|c|}{ EXPERIÊNCIA } & \multicolumn{1}{|c|}{ LOCAL } & INÍCIO & INICIATIVA \\
\hline $\begin{array}{l}\text { Lote Agroecológico de Produ- } \\
\text { ção Orgância (LAPO) }\end{array}$ & Assto. Mártires de Abril & 2005 & Familiar \\
\hline $\begin{array}{l}\text { Lote Agroecológico Ernesto e } \\
\text { Taiguara (LAET) }\end{array}$ & Assto. Mártires de Abril & 2014 & Familiar \\
\hline Sítio Raio de Sol & Assto. Mártires de Abril & 2014 & Familiar \\
$\begin{array}{l}\text { Sistema Agroecológico de } \\
\text { Produção Orgânica (SAPO) }\end{array}$ & Assto. João Batista & 2011 & $\begin{array}{l}\text { Familiar } / \\
\text { Coletiva }\end{array}$ \\
\hline $\begin{array}{l}\text { Lote Agroecológico de Sobre- } \\
\text { vivência Orgânica (LAESO) }\end{array}$ & Acamp. Olga Benário & 2015 & Familiar \\
\hline Sistema Agroflorestal (SAF) & Acamp. Olga Benário & 2016 & Coletiva \\
\hline Banco de Sementes & Acamp. Jesus de Nazaré & 2016 & Coletiva \\
\hline Coletivos de produção & Assto. Carlos Lamarca & $\begin{array}{l}2013 \text { - } \\
2016\end{array}$ & Coletiva \\
\hline Lotes familiares & Assto. Carlos Lamarca & $\begin{array}{l}2014- \\
2016\end{array}$ & Familiar \\
\hline Grupos de produção & $\begin{array}{l}\text { Acamp. Carlos Mari- } \\
\text { ghella }\end{array}$ & 2015 & Coletiva \\
\hline
\end{tabular}

Fonte: Trabalho de campo (2016).

O Lote Agroecológico de Produção Orgânica (LAPO) tem sido uma referência, pois foi a primeira experiência concreta e intencional de desenvolver uma produção agroecológica no MST-Pará. É uma experiência de produção familiar, mas com todo um processo de socialização e formação, baseado na Educação Popular, o que fez com que essa idéia de lotes familiares, com identidade visual, inclusive, começasse a se espalhar pela Regional Cabana (ROCHA et al., 2015).

O Lote Agroecológico Ernesto e Taiguara (LAET), assim como o LAPO, está localizado no Assentamento Mártires de Abril (Mosqueiro-BelémPará) e é, igualmente, uma experiência familiar. Ainda em estádio inicial de transição agroecológica, já coloca em prática vários princípios e, do ponto de vista organizativo, está articulando um grupo de mulheres do assentamento, pautando pelo trabalho com plantas medicinais.

Anteriormente ao LAET, surgiu em 2011, o Sistema Agroecológico de
Produção Orgânica (SAPO). Este, localizado no Assentamento João Batista II, em Castanhal-PA, é uma experiência que conta com duas famílias e que, como já amplamente exposto pelos responsáveis, se propõe a ser um espaço cada vez mais coletivo, à disposição do MST e das organizações da classe trabalhadora. Mesmo em um estádio mais avançado na transição agroecológica, ainda apresenta muitos limites quanto à estrutura, principalmente no que tange à questão da água. O SAPO é "fruto de um debate interno da organização, assumindo uma reflexão coletiva crucial para a indução do processo" (CRUZ, 2016, p. 40).

Por fim, existem as experiências coletivas do assentamento Carlos Lamarca em Capitão Poço, em parceria com a UFRA/Campus Capitão Poço, mais especificamente o NEA-UFRA-CCP. Neste processo, estão organizados três grupos, com pessoas comuns aos três ou somente em um deles. Os grupos são: viveiro de mudas, principalmente frutíferas; horta, neste caso é um grupo de mulheres e; criação de galinha caipira, o coletivo mais recente. Além disso, foram ainda criadas três unidades de referência em Sistemas Agroflorestais (SAF).

Outras experiências foram nascendo, como o Sítio Raio de Sol no assentamento Mártires de Abril, o Lote Agroecológico de Sobrevivência Orgânica no acampamento Olga Benário, ou outras experiências familiares em acampamentos. Cada uma com seu nível de transição agroecológica e com pouca, ou quase nenhuma, sistematização.

É importante ressaltar que parte destas experiências tiveram um impulso com o Curso de Formação em Agroecologia da Regional Cabana, ocorrido no segundo semestre de 2014, em parceria com o Instituto Federal do Pará (IFPA), campus Castanhal. Iniciativa formativa importante e, como tantas outras historicamente no Movimento, impulsionadora de processos.

A quinta limitação está ligada à forma de trabalho, que na maioria das vezes é individual, envolvendo apenas a família isolada no lote familiar. Por vezes, como característica da forma camponesa de produção, ocorrem formas simples de cooperação, como mutirões ou trocas de diárias.

O trabalho cooperado é um desafio, hoje nós não temos na prática um trabalho cooperado constante, então isso também é uma dificuldade. Como Mamede dizia, 'Agroecologia não se faz sozinho'. (Assentada D).

O individualismo, base da sociedade capitalista e reforçado pela 
propriedade privada, tenta ser contraposto pelo MST, com a busca de formas coletivas de organização, a exemplo dos grupos ou coletivos organizativos na fase de acampamento. Porém visualiza-se em um dado momento a dificuldade de manutenção destes coletivos, seja por uma questão cultural, seja pela diversidade de objetivos que afloram na fase de assentamento, como expresssam os depoimentos abaixo:

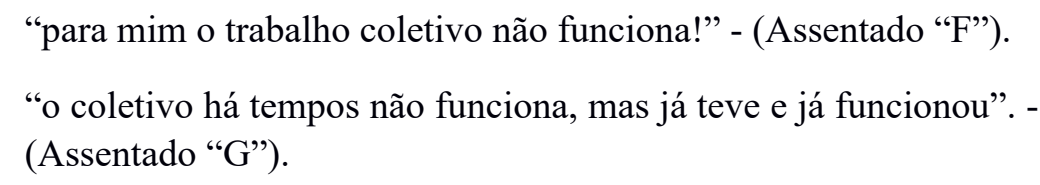

Contudo, se faz necessário avançar no processo de despertar desta consciência coletiva, pois como afirma Iasi (2006), este estádio de consciência individual pode em um dado momento evoluir para uma consciência de grupo, de classe, até alcançar a universalidade.

É interessante ressaltar a diferença entre acampamento e assentamento, pois quando estão em acampamento, as famílias vivem de forma mais coletiva, com parte da área de produção desenvolvida com trabalho coletivo, por núcleo de famílias; a posse da terra é coletiva. Quando passam para assentamento, por mais que o MST defenda a Concessão de Direito Real de Uso (CDRU) da terra, cada família vai para o seu lote, e a força da propriedade privada retorna como força material, dificultando a organização das famílias, o trabalho coletivo e formas mais avançadas de cooperação.

A propriedade privada, para Marx (2006, p. 142), reduziu os seres humanos ao sentido do ter, alienando-os ao ponto de tornarem-se "tão estúpidos e parciais que, um objeto só é nosso quando o temos, quando existe para nós como capital ou quando por nós é diretamente possuído, comido, bebido, transportado no corpo, habitado etc., ou melhor, quando é utilizado". Portanto, a supressão da propriedade privada, para Marx (2006, p. 142, grifos do autor), se constitui na "emancipação total de todos os sentidos e qualidades humanas. Mas só é esta emancipação porque os referidos sentidos e propriedades se tornaram humanos, tanto do ponto de vista subjetivo como objetivo". Isso é bem caracterizado na fala da assentada "E":

“quando a gente tá no processo de acampamento, é muito incentivado o processo de trabalho voluntário, do coletivo, de construção coletiva. Como a terra ainda não foi conquistada, esse processo de acampamento é mais vivo, essa solidariedade, essa construção desse novo. Porém quando a gente tá no processo de assentamento, que é um processo de transição, que a gente conquista a terra e as pessoas acabam indo cuidar do seu próprio patrimônio, a gente tem um pouco mais de dificuldade nesse trabalho coletivo".

Esse fato também pode ser comprovado pela própria observação das áreas de reforma agrária que participaram da pesquisa, dos seis acampamentos iniciais, todos conseguiram garantir a realização das atividades planejadas neste trabalho e ter boa participação das famílias. Já com os assentamentos foi diferente, dos seis iniciais, somente quatro garantiram a realização das atividades, sendo que três com baixa participação das famílias.

Contudo, pela intencionalidade do MST, formas de organização $e$ trabalho coletivo aparecem e contribuem no avanço da Agroecologia dentro do movimento. Como resultado do processo de pesquisa-ação, houve a reconstituição da coordenação regional do SPCMA (Figura 3).

Outro exemplo é o caso do grupo de trabalho coletivo do acampamento Carlos Marighella (Figura 4) que vem trabalhando com hortaliças e tem uma dinâmica de trabalho, com divisão de dias de trabalho e mutirões em área coletiva. Desta forma concordando com Iasi (2006), pois o sentimento de pertença a um grupo faz o indivíduo se ver como parte de uma coletividade maior, reforçando sua identidade e experimentando uma força na ação que antes não possuia.

a gente está aí formando, organizando grupo de trabalho e nessa perspectiva de se somar e de fazer essa transição cada vez mais forte - (Assentado C)

Dentre as seis limitações, o capitalismo na agricultura pode ser considerada a principal, demonstrada em todas as entrevistas e em diversas falas durante as atividades. Nesse sentido vale o pensamento de Tse-Tung (2004), de que, em cada etapa do desenvolvimento de um processo existe uma contradição principal, a qual desempenha o papel diretor do mesmo. E neste caso, a contradição entre o agronegócio, que representa as ações do capitalismo na agricultura, e as práticas e princípios da Agroecologia, que representa uma resistência camponesa.

Esta pode ser considerada a principal limitação pelo fato de determinar as outras limitações anteriormente discutidas. Por exemplo, a manutenção 
Figura 3 - Reunião do coletivo regional do SPCMA.

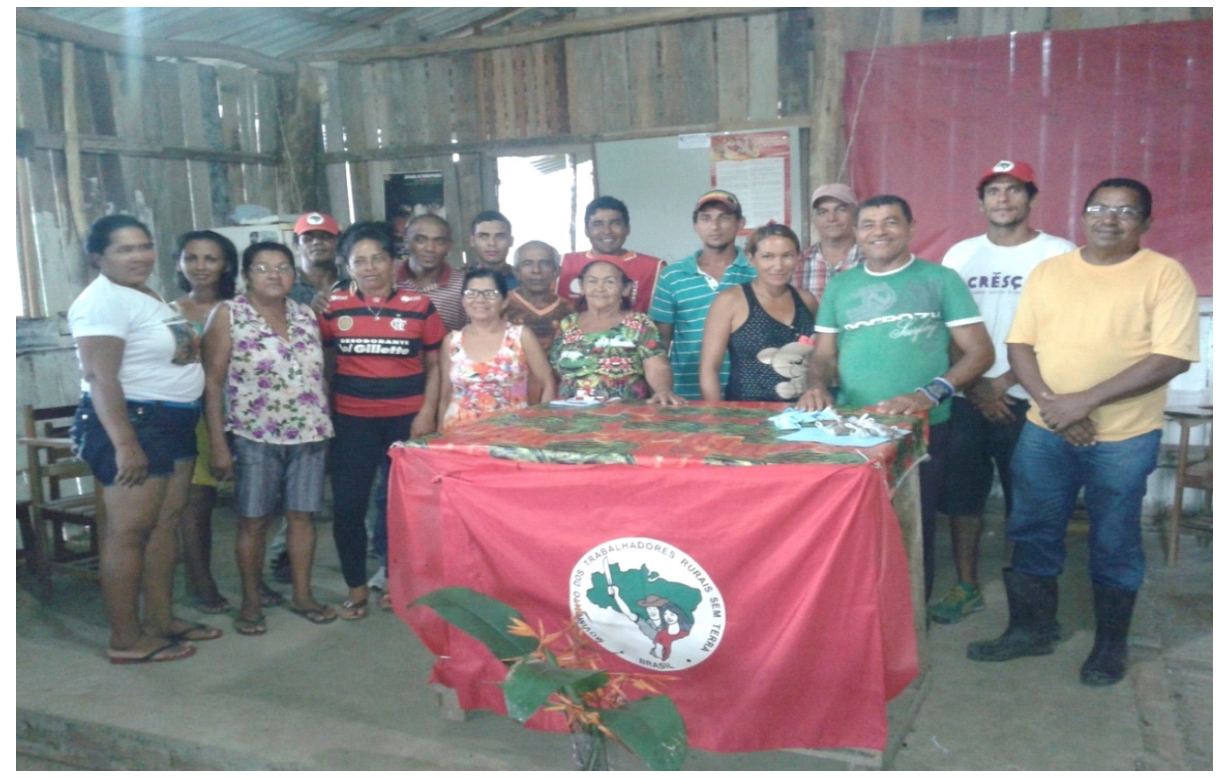

Fonte: Trabalho de campo (2016).

Figura 4 - Grupo de trabalho coletivo do acampamento Carlos Marighella

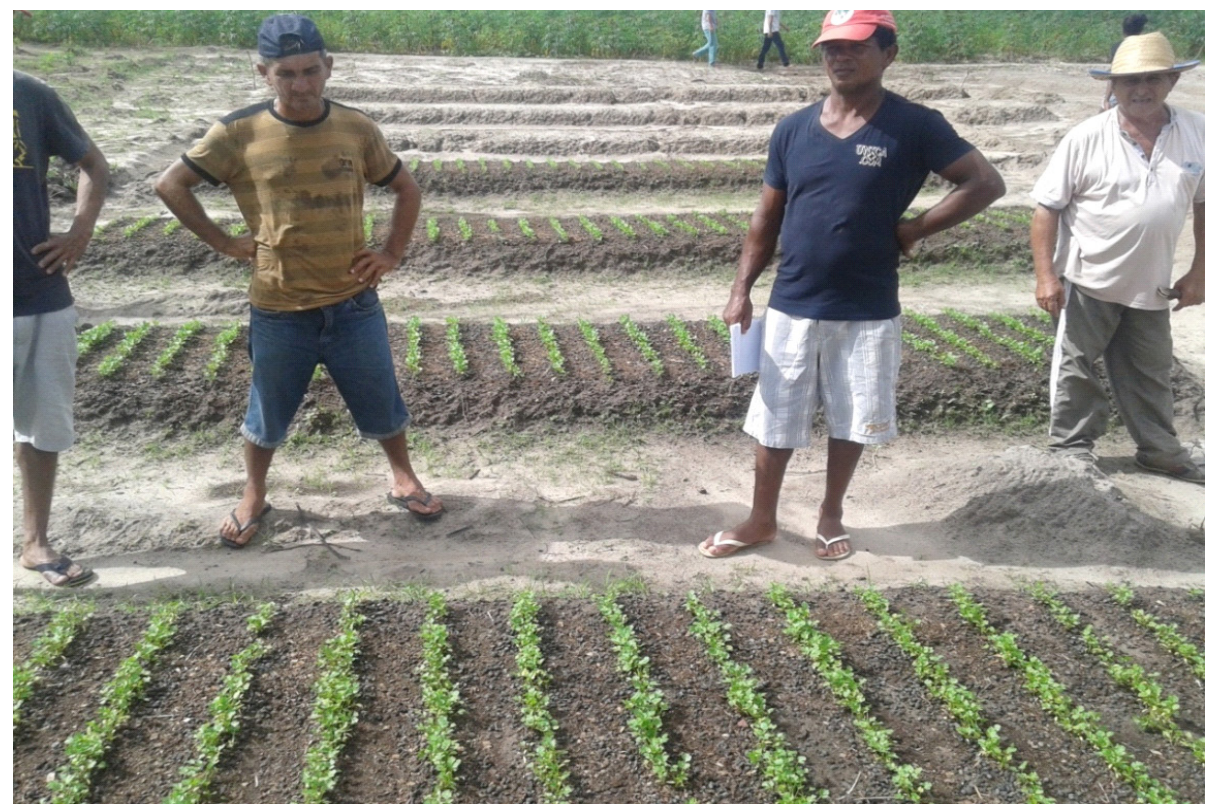

Fonte: Trabalho de campo (2016). da estrutura agrária brasileira, a orientação dos créditos na área agrícola beneficiando os grandes produtores, a assistência técnica comprometida em repassar o pacote da Revolução Verde e ideologia do lucro imediato, são todos conseqüências das ações do capital da agricultura.

"No sistema agroecológico cabe você pensar nessa forma de produzir uma agricultura, fazer uma produção de alimento saudável, sem agredir o meio ambiente (...). É uma forma de resistir contra o monocultivo, o capital no campo" - (Assentada "D”, grifo nosso).

Cabe aqui uma discussão sobre a postura de resistência dos movimentos socialistas e a necessidade de uma ofensiva contra o capital. Para Mészáros (2002), esses movimentos sempre se posicionaram com uma postura defensiva, sendo que o momento histórico deve ser de engajamento e construção de estratégias de uma ofensiva socialista em consonância com as condições objetivas.

Para o Dirigente "B" (grifo nosso) existe uma tensão entre o modelo capitalista para o campo e as agriculturas de base ecológica, pois

"não é possível a coexistência entre agronegócio e Agroecologia, então o maior desafio é derrotar o projeto de morte do capital no campo".

Observa-se aqui a Agroecologia como uma estratégia, que pode vir a ser, utilizando as palavras de Mészáros (2002, p. 845), “a viabilidade de uma ofensiva estratégica que visa à transformação radical da ordem sociometabólica estabelecida".

Concordando com essa questão, para Rosset (2016), existe uma guerra entre o campo e o agronegócio, e a estratégia camponesa da Agroecologia está para além da resistência, quando transforma os territórios camponeses em algo diferente do território do agronegócio, da mineração e do capital.

\section{Conclusões}

Este trabalho de pesquisa-ação possibilitou identificar seis limites e seis perspectivas no processo de construção da Agroecologia dentro de um movimento social de luta pela terra no nordeste paraense. Os limites encontrados foram o latifúndio, a expropriação do conhecimento, falta de uma assistência técnica agroecológica, o acesso às políticas públicas, o 
trabalho individual e o capitalismo na agricultura.

Apesar das limitações e dificuldades para se construir a Agroecologia nos assentamentos do MST no Nordeste Paraense, existem perspectivas positivas, materializadas na luta pela terra, no diálogo de saberes, na assessoria técnica própria dos movimentos sociais, na construção de iniciativas de autonomia, no trabalho cooperado juntamente com organização coletiva e na construção de uma ofensiva camponesa.

As perspectivas mostram que, para além da intencionalidade do MST, que existe e está registrada em seu programa agrário, a Agroecologia é uma alternativa que possibilita autonomia e soberania alimentar do campesinato e segurança alimentar para o campo e a cidade.

Algumas questões não apareceram na coleta de dados, mas são de bastante importância para a construção da Agroecologia, como as questões de gênero e as questões geracionais, necessitando, portanto, estudos dedicados e focados a estes temas.

A limitação principal, ou seja, as ações do capitalismo no campo geram a contradição entre agronegócio e a agricultura camponesa agroecológica, o que requer que os movimentos de transformação da sociedade saiam da lógica da resistência para a construção de uma perspectiva de ofensiva camponesa, trabalhando e produzindo com base nos princípios agroecológicos.

O MST, com toda a representatividade social que exerce, deve sistematizar, fortalecer e continuar a construir experiências agroecológicas familiares e coletivas. Sendo de fundamental importância uma pedagogia libertadora nesse processo de construção. A metodologia de pesquisaação utilizada nesse trabalho pode ser associada à forma organizativa do movimento, construindo as brigadas agroecológicas para assumir essa tarefa.

É importante focar nas experiências existentes e que já carregam uma intencionalidade de desenvolver uma agricultura agroecológica, otimizando recursos humanos e financeiros. Vale ressaltar que a lógica de nomear as experiências familiares, prática presente na regional Cabana do MST, tem contribuído para a autoestima das famílias responsáveis pelas mesmas, bem como para a socialização e divulgação da Agroecologia, dentro e fora do Movimento.

Para a construção de uma proposta anticapitalista, é necessário reafirmar e praticar a Agroecologia como base da agricultura camponesa, sem maisvalia, sem exploração da força de trabalho e sem reificação. Ou ao contrário, o capital se apropriará de conceitos e técnicas da agricultura agroecológica, da mesma forma que se apropriou da agricultura orgânica.

O pessimismo das ideias se combate com o otimismo das ações. Portanto, os limites apresentados só serão superados por uma práxis transformadora. Assim, a Agroecologia só se constrói com luta, relações sociais dialógicas, autonomia, organização e trabalho coletivo.

\section{Referências Bibliográficas}

ALTIERI, M. Agroecologia: bases científicas para uma agricultura sustentável. $3^{\text {a }}$ ed. São Paulo, Rio de Janeiro: Expressão Popular, AS-PTA, 2012. $400 \mathrm{p}$.

AZEVEDO, L. F.; NETTO, T. A.; HILLIG, C. Perspectivas agroecológicas no desenvolvimento de uma comunidade rural: o caso de Cerro Pelado/ Uruguai. Rev. Elet. em Gest., Educ. e Tecn. Amb., v. 11, n. 11, p. 22732279, jun., 2013.

BORSATTO, R. S. ; CARMO, M. S. A Construção do Discurso Agroecológico no Movimento dos Trabalhadores Rurais Sem-Terra (MST). Rev. Econ. Soc. Rur., Piracicaba-SP, vol. 51, n 4, p. 645-660, Out/ Dez 2013.

BRASIL. Ministério do Desenvolvimento Agrário. Política Nacional de Assistência Técnica e Extensão Rural. Brasília, 2007, 26 p.

CAPORAL, F. R. O caráter social e a importância da extensão rural. In:_ (Coord.). Extensão Rural e Agroecologia: temas sobre um novo desenvolvimento rural, necessário e possível. Brasília: MDA, 2007a. p. $57-62$.

. A extensão rural no rio grande do sul: do modelo "made in usa" ao paradigma agroecológico. In: (Coord.). Extensão Rural e Agroecologia: temas sobre um novo desenvolvimento rural, necessário e possível. Brasília: MDA, 2007b. p. 83-101.

. Bases para uma nova ATER pública. In: (Coord.). Extensão 
Rural e Agroecologia: temas sobre um novo desenvolvimento rural, necessário e possível. Brasília: MDA, 2007c. p. 103-125.

COORDENAÇÃO Nacional do MST. O papel estratégico da agroecologia para o MST. Rev. Sem Ter., edição especial agroecologia, São Paulo, p. 10-14, 2010.

CRUZ, B. L. Agricultura camponesa e agroecossistemas com princípios agroecológicos: um olhar sobre o nordeste paraense. 2016. f. Trabalho de Conclusão de Curso (Graduação em Zootecnia) - Universidade Federal Rural da Amazônia, Belém-PA, 2016.

EMPSON, M. Land and labour: marxism, ecology and human history. London: Bookmarks, 2014. 319 p.

FAO/ONU - Food and Agricultura Organization of the United Nations.

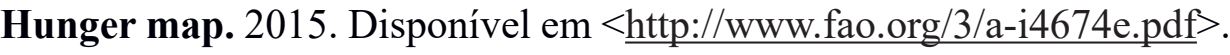
Acessado em 03 out. 2016.

FARIA, L. M. S. Aspectos gerais da agroecologia no Brasil. Rev. Agrogeoamb. v. 6, n. 2, ago., 2014, p. 101-112.

FREIRE, P. Extensão ou comunicação?. $15^{\mathrm{a}}$ ed. São Paulo: Paz e Terra, 2011. $131 \mathrm{p}$.

FREIRE, P. Pedagogia do oprimido. Rio de Janeiro: Paz e Terra, 2003 $184 \mathrm{p}$.

GLIESSMAN, S. R. Agroecologia: processos ecológicos em agricultura sustentável. $3^{\mathrm{a}}$ ed. Porto Alegre: UFRGS, 2005. 653 p.

GUEDES, C. M. G.; FERREIRA, R. L. C. O novo desafio da ATER na amazônia: estar junto com os novos protagonistas do desenvolviento economicamente dinâmico e ambientalmente sustentável. In: MONTEIRO, D. M. C.; MONTEIRO, M. A (orgs.). Desafios na amazônia: uma nova assistência técnica e extensão rural. Belém: NAEA, 2006. p. 15-26.
IASI, M.L. As metamorfoses da consciência de classe: o PT entre a negação e o consentimento. São Paulo: Expressão Popular, 2006. 582 p.

INSTITUTO Brasileiro de Geografia e Estatística. Censo agropecuário 2006. Disponível em: $<$ http://biblioteca.ibge.gov.br/visualizacao/ periodicos/51/agro_2006.pdf $>$. Acesso em: 14 nov. 2016.

LÖWY, M. O que é ecossocialismo?. 2a ed. São Paulo: Cortez, 2014. 128 p.

MACHADO, L. C. P.; MACHADO FILHO, L. C. P. A dialética da agroecologia. São Paulo: Expressão Popular, 2014. 360 p.

MINISTÉRIO DA AGRICULTURA, PECUÁRIAE ABASTECIMENTO MAPA. Plano Agrícola Pecuário 2017/2018. Disponível em: $<\underline{\text { http: } / / \mathrm{www} .}$ agricultura.gov.br/assuntos/sustentabilidade/plano-agricola-e-pecuario/ arquivos-pap/folder-pap-2017-18>. Acesso em Julho de 2017.

MARQUES, V. P. M. A.; GROSSI, M. E. del; FRANÇA, C. G. O censo 2006 e a reforma agrária: aspectos metodológicos e primeiros resultados. Brasília: MDA, 2012. 108 p.

MARTINS, A. Agroecologia: modelo que une alimentos saudáveis e luta por reforma agrária. Rev. Sem Ter., edição especial agroecologia, São Paulo, p. 36-37, 2010.

MARX, K. Manuscritos econômicos-filosóficos. São Paulo: Martin Claret, $2006.198 \mathrm{p}$.

MÉSZÁROS, I. Atualidade histórica da ofensiva socialista. In: . Para além do capital. São Paulo: Boitempo, 2002. p. 787-860.

MINAYO, M. C. S. O desafio do conhecimento: pesquisa qualitativa em saúde. $7^{\text {a }}$ ed. São Paulo: Hucitec; Rio de Janeiro: Abrasco, 2000.

MOURA, V. Abordagem de reforma agrária. São Paulo: Pioneira, 1968. $318 \mathrm{p}$. 
MOVIMENTO dos Trabalhadores Rurais Sem Terra. Normas gerais do MST. In: Documentos. Brasília-DF: MST, 2016. p. 27-36.

Programa agrário do MST. $4^{\mathrm{a}}$ ed. São Paulo: MST, 2015. 52 p.

NASCIMENTO, I. R. et. al. Diversificação das atividades produtivas e as perspectivas de adoção de técnicas agroecológicas em sistema leiteiro no semiárido sergipano. Cad. de Agroecol., vol 9, n. 4, nov. 2014. Disponível

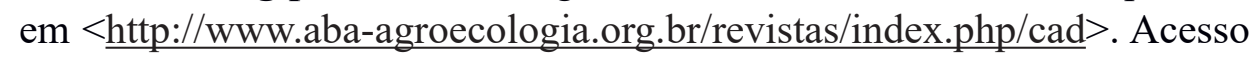
em 23 out. 2016.

NUNES, S. P. Introdução. In: crítica. Ijuí: Unijuí, 2014. p. 17-22.

(Org). Agroecologia: uma abordagem

NUNES, S. P.; GRÍGOLO, S. C.; GNOATTO, A. A. A reorganização dos serviços de ATER no sul do Brasil diante do desenvolvimento capitalista na agricultura. In: NUNES, S. P.; GRÍGOLO, S. C. (Orgs). Assistência técnica e extensão rural no sul do Brasil. Ijuí: Unijuí, 2013 p. 21-43.

PADULA, J. et al.. Os caminhos da agroecologia no Brasil. In: GOMES, J. C. C.; ASSIS, W. S. Agroecologia: princípios e reflexões conceituais. Brasília-DF: Embrapa, 2013. p. 37-72.

PENNA, C.; ROSA, M. C. Estado, movimentos e reforma agrária no Brasil: reflexões a partir do Incra. Rev. Lua Nov., p. 57-86, 2015.

PIZETTA, A. J. A formação de quadros políticos: elaboração teórica, experiências e atualidade. In: ESCOLA Nacional Florestan Fernandes. A política de formação de quadros. Guararema: ENFF, 2007. p. 85-97.

PLOEG, J. D. van der. Camponeses e impérios alimentares: lutas por autonomia e sustentabilidade na era da globalização. Porto Alegre: editora da UFRGS, 2008. 376 p.

PRADO JR; C. A questão agrária no brasil. $2^{\mathrm{a}}$ ed. São Paulo: editora Brasiliense, 1979. 188 p.
ROCHA, A. C. O. O Movimento dos Trabalhadores Rurais Sem Terra no Pará: da luta posseira à construção de um bloco histórico camponês (1984-2009). 2009. 47 f. Monografia (Especialização em Movimentos Sociais) - Universidade do Estado do Pará, Belém, 2009.

O MST e a luta pela terra no Pará. Marabá: Iguana, 2015. 76 p.

ROCHA, A. C. O. et al. Agroecologia na amazônia: uma alternativa para o sistema de "derruba e queima", estudo de caso do lote agroecológico de produção orgânica (LAPO). Cad. Agroecol. v. 10, n. 3, 2015. Disponível em $<$ http://www.aba-agroecologia.org.br/revistas/index.php/cad/article/ view/17379/11340>. Acesso em: 25 nov. 2016.

ROCHA, A. C. O.; ZULIANI, M. Q. Saúde e reforma agrária.Rev. Multiplicações. Belém: UEPA, n. 3. p. 86-88, 2007.

ROSA, M. C. A journey with the movimento dos trabalhadores rurais sem terra (MST) across Brazil and on to South Africa.Etud. Rural., v. 196, p. 43-55, 2015.

ROSSET, P. M. Las recetas no funcionan, lo que se propone son princípios. Rev. Biodivers., n. 90, p. 5-10., nov., 2016

ROSSET, P. M.; MARTÍNEZ TORRES, M. E.. Agroecología, territorio, recampesinización y movimientos sociales. Rev. Invest. Cien. Jan.-jun. 2016, n. 47 , v. 25 , p. $275-299$.

SÁ, T. D. A.; SILVA, R. O. Para além do interdisciplinar: a agroecologia como uma perspectiva transdisciplinar para a agricultura na Amazônia. In: VIEIRA, I. C.G.; TOLEDO, P. M.; SANTOS JÚNIOR, R. A. O. (Orgs.) Ambiente e sociedade na Amazônia: uma abordagem interdisciplinar. Rio de Janeiro: Garamond, 2014.

SECRETARIA ESPECIAL DA AGRICULTURA FAMILIAR E DO DESENVOLVIMENTO AGRÁRIO - SEAD. Plano Safra da Agricultura Familiar 2017/2020. 2017. Disponível em: <http://www.mda.gov.br/ sitemda/plano-safra-da-agricultura-familiar-20172020>. Acesso em Julho de 2017. 
SEVILLA GUZMÁN, E.; MOLINA, M. G. Sobre a evolução do conceito de campesinato. $3^{\text {a }}$ ed. São Paulo: Expressão Popular, 2008. 96 p.

SILVA, M.E.P. et al. Diagnóstico e planejamento de desenvolvimento do território rural do nordeste paraense. Capanema-PA: MDA, 2006. 134 p.

STEDILE, J. P. Latifúndio: o pecado agrário brasileiro. $2^{\mathrm{a} e d . ~ S a ̃ o ~ P a u l o: ~}$ Movimento dos Trabalhadores Rurais Sem Terra, 2003.

THIOLLENT, M. Metodologia da pesquisa-ação. $18^{a}$ ed. São Paulo: Cortez, 2011. $132 \mathrm{p}$.

TRIVIÑOS, A. N. S. Introdução à pesquisa em ciências sociais: a pesquisa qualitativa em educação. São Paulo: Atlas, 1987. 176 p.

TSE-TUNG, M. Sobre a prática e sobre a contradição. São Paulo: Expressão Popular, 2004. 95 p. 